\title{
Notes on the vocalizations of Desert Warbler (Sylvia nana)
}

Peter Boesman

In the following we briefly analyze and compare voice of the two races of Desert Warbler (Sylvia nana). We also try to quantify the extent of any vocal differences using the criteria proposed by Tobias et al. (2010), as a support for taxonomic review. We have made use of sound recordings available on-line from Xeno Canto (XC) and Macaulay Library (ML).

Song of both races is a short warbled phrase, sometimes preceded by a dry rattle.

Some examples from the relatively few available recordings:

nana
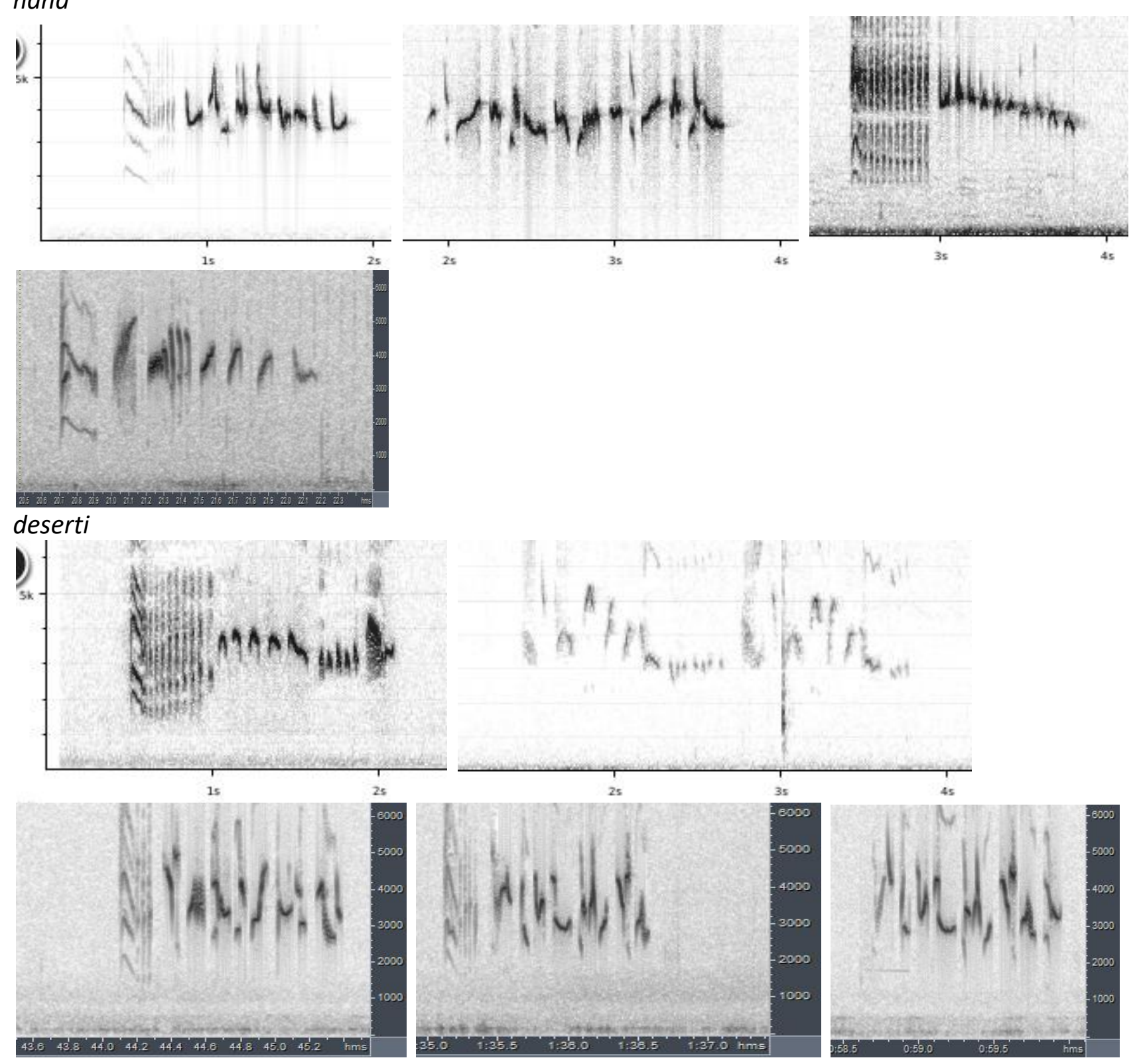

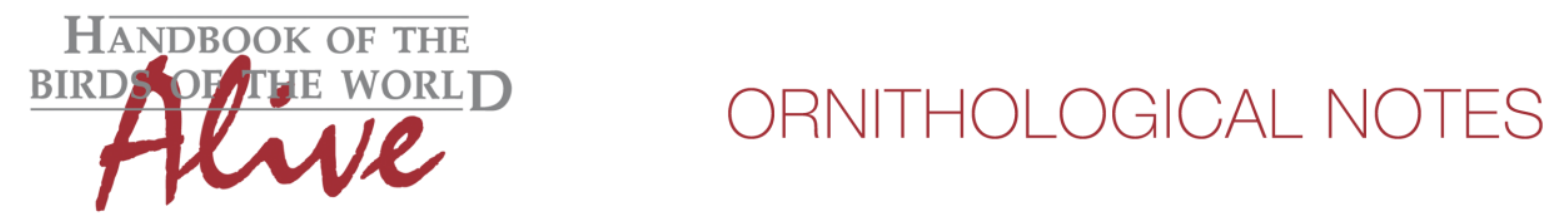

It is clear from the above examples that song of both races is quite similar (with a near identical introductory rattle call). All basic sound parameters are about the same (song length, note length, $\max / \mathrm{min}$ freq.,..), frequency range of nana possibly on average slightly smaller.

A more thorough analysis, including a comparison of individual note shapes, would be needed to find any diagnostic differences, but obviously many more recordings would be needed for such an analysis. A possibility is e.g. that the frequency range of individual notes in nana is somewhat smaller than in deserti. In any case, such differences would be quite subtle and would not lead to a considerable vocal score when applying Tobias criteria.

These findings are rather contradictory to a previous analysis, in which song was stated to be very different (Shirihai et al. 2001), and which was subsequently taken over in HBW (Aymí et al. 2016). Song of nominate is described as being much more stereotyped and less varied, as "krrrrrr-ti-ti-ti-ti-titi-teu", while that of deserti far more rich, less clean and fluting than nominate. The authors also give a single sonogram per race, but their Figure 2 of nana hardly matches their description (it lacks e.g. both the initial rattle and ending 'teu', is thus apparently not very illustrative and contradicts their own statement of song being stereotyped). The description of deserti states that its song ends with a rising whistle (which indeed can be seen on their Figure 3), but none (!) of the five examples of the sonograms depicted above for deserti seem to do so. It would thus seem that these voice descriptions have rather been based on a few individual cases and can't be seen as generic for the race.

We reproduce as an additional illustration some recordings with a finer time/freq scale:

nana

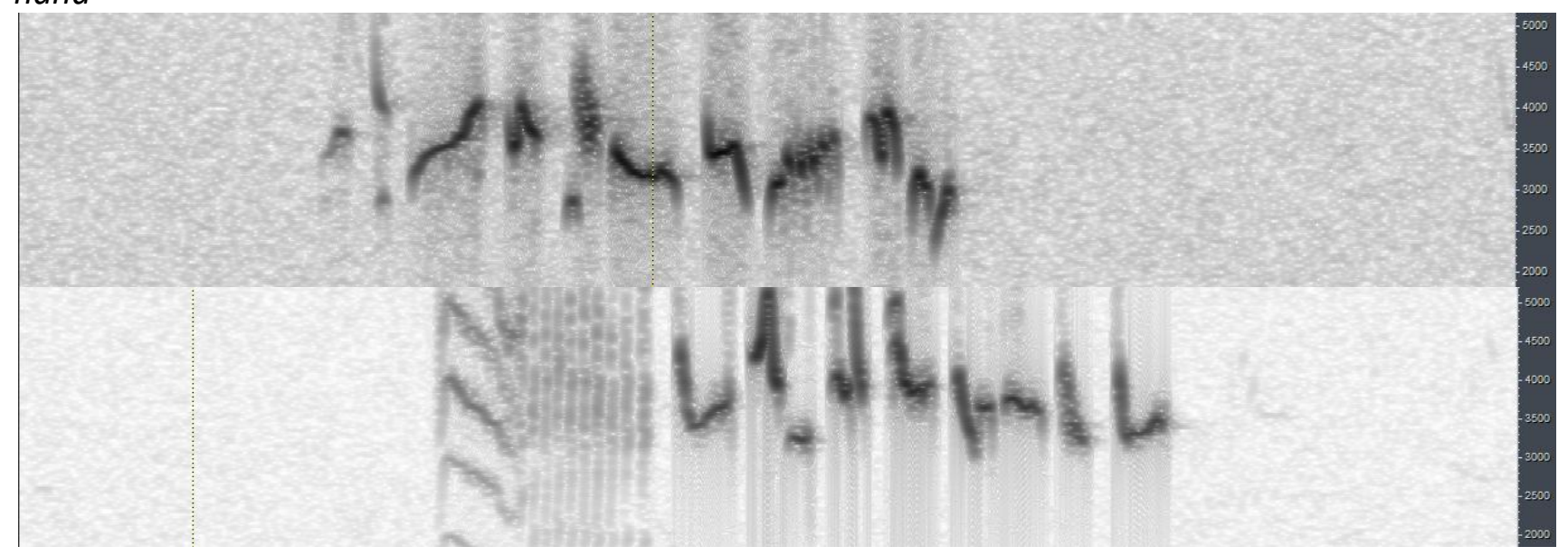

deserti 

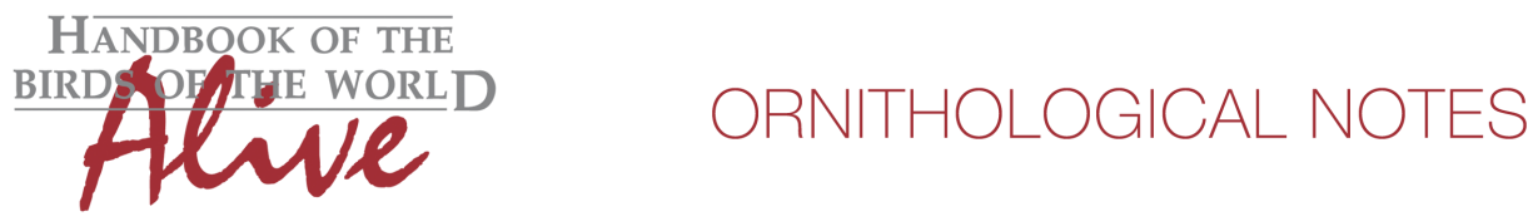

This illustrates quite convincingly that the level of variation within each race is of a similar magnitude as the variation among both races.

We can only conclude that the available on-line recordings do not confirm the 'large vocal differences' mentioned in the literature. Applying Tobias criteria based on available recordings can't produce much more than a zero score.

It seems recommended to redo a thorough vocal analysis when more recordings become available.

This note was finalized on 9th March 2016, using sound recordings available on-line at that moment. We would like to thank in particular the sound recordists who placed their recordings for this species on XC and ML: Oscar Campbell, Jose Luis Copete, Dave Farrow, Thijs Fijen, Patrick Franke, Peter Hosner, Albert Lastukhin, Tero Linjama, Alain Malengreau, Cedric Mroczko, Manuel Schweizer, Arnoud Van den Berg and Herman Van Oosten.

\section{References}

Aymí, R. \& Gargallo, G. (2016). Desert Warbler (Sylvia nana). In: del Hoyo, J., Elliott, A., Sargatal, J., Christie, D.A. \& de Juana, E. (eds.). Handbook of the Birds of the World Alive. Lynx Edicions, Barcelona. (retrieved from http://www.hbw.com/node/58960 on 9 March 2016).

Shirihai, H., Gargallo, G. \& Helbig, A.J. (2001). Sylvia Warblers. Identification, Taxonomy and Phylogeny of the Genus Sylvia. Princeton University Press, New Jersey.

Tobias, J.A., Seddon, N., Spottiswoode, C.N., Pilgrim, J.D., Fishpool, L.D.C. \& Collar, N.J. (2010). Quantitative criteria for species delimitation. Ibis 152(4): 724-746.

\section{Recommended citation}

Boesman, P. (2016). Notes on the vocalizations of Desert Warbler (Sylvia nana). HBW Alive Ornithological Note 260. In: Handbook of the Birds of the World Alive. Lynx Edicions, Barcelona. (retrieved from http://www.hbw.com/node/1251590 on 4 October 2016). 